\title{
FRACTURE-DISLOCATION OF THE THORACIC SPINE DURING SECOND TRIMESTER OF PREGNANCY: CASE REPORT AND LITERATURE REVIEW
}

Alberto Ofenhejm Gotfryd', Fernando José Franzin², Patrícia Rios Poletto ${ }^{3}$, Nicola Jorge Carneiro Neto², Roberto César Nogueira Júnior ${ }^{4}$, Luiz Carlos Lopes Ferreira Júnior ${ }^{5}$

\begin{abstract}
Spinal fractures associated with spinal cord injury rarely affect pregnant patients. The authors present the case of a 20 -year-old woman in her $20^{\text {th }}$ week of pregnancy, who suffered fracture-dislocation of the thoracic spine (T4-T5) and underwent decompression, reduction and posterior fusion with pedicle screws. Despite the complete spinal cord injury presented, the pregnancy progressed uneventfully and resulted in birth via normal delivery of a healthy newborn at term. Some particular features of
\end{abstract}

this case, like the care needed in using ionizing radiation, the surgical approach and delivery, use of steroids and pregnancy complications in such patients are discussed here. Only a multidisciplinary team composed by physicians from different specialties (spinal surgeons, obstetricians and physiatrists), nurses and physiotherapists is capable of assisting pregnant patients with spinal cord injuries satisfactorily.

Keywords - Spinal Fractures; Pregnancy; Spinal Cord Injuries; Radiation, Ionizing

\section{INTRODUCTION}

Spinal fractures associated with spinal cord injuries rarely affect pregnant patients ${ }^{(1-6)}$. When such events occur in this population, this generally leads to early termination of the pregnancy, with an unviable fetus. It has been estimated that in Brazil, more than 10,000 new cases of spinal cord injury occur in adults every year, and most of these are due to trauma ${ }^{(7-9)}$. In addition, trauma during pregnancy is one of the main causes of non-obstetric maternal death ${ }^{(10,11)}$. In the following, we present a report on a case of a pregnant woman who suffered fracture and dislocation of the thoracic spine (T4-T5) and underwent decompression, reduction and arthrodesis via a posterior route, using pedicle screws. Despite the complete spinal cord lesion presented, the pregnancy progressed without intercurrences and culminated with the birth, by means of normal delivery, of a healthy newborn at term. Some particular features, such as the use of ionizing radiation, surgical access route, delivery route, corticoid therapy and gestational complications in patients under these conditions will be discussed in this article.

\section{CASE REPORT}

The patient was 20 years old, with a normal pregnancy of 20 weeks, and was run over by a car. She arrived at the emergency services one hour after the event, brought by an ambulance on a rigid stretcher, with a neck collar fitted. She presented a condition compatible with medullary shock, showing absence of sensitivity, motricity and reflexes below the T6 level. She underwent a protocol for initial assessment of multiple trauma victims, in accordance with the ATLS standards ${ }^{(12)}$, and complementary

1 - PhD. Chief Physician of the Spinal Disorders Group, Santa Casa da Misericórdia de Santos, Santos, SP, Brazil.

2 - Attending Physician in the Spinal Disorders Group, Santa Casa da Misericórdia de Santos, Santos, SP, Brazil.

3 - PhD. Adjunct Professor of the Physiotherapy Course, Federal University of São Paulo, Baixada Santista Campus, Santos, SP, Brazil.

4 - Adjunct Professor of Gynecology and Obstetrics, Metropolitan University of Santos, Santos, SP, Brazil.

5 - Orthopedist and Traumatologist, Santa Casa da Misericórdia de Santos, Santos, SP, Brazil.

Work developed in the Department of Orthopedics and Traumatology, Santa Casa da Misericórdia de Santos, Santos, SP.

Correspondence: Avenida Ana Costa 259/51, Encruzilhada, 11060-001 Santos, SP. E-mail: albertocoluna@yahoo.com.br

Work received for publication: June 21, 2011; accepted for publication: August 4, 2011.

The authors declare that there was no conflict of interest in conducting this work 
orthopedic and obstetric assessments. She remained in a hemodynamically stable condition, without vaginal bleeding and with normal fetal heartbeats (148 bpm). Radiographs on the spine showed fracturing and dislocation of the thoracic spine at the level T4-T5. A computed tomography scan on the thoracic spine (using a lead apron to protect the abdomen) was performed to examine the injury better and aid in planning the surgical treatment (Figure 1). An obstetric ultrasound examination was also performed, and this showed that there was a single live fetus with mean fetal biometrics compatible with an age of 20 weeks, a posterior placenta without signs of detachment and an amniotic fluid index that was normal for the gestational age.

The patient then underwent operative treatment of the T4-T5 spinal fracture and dislocation on an emergency basis. She was positioned in horizontal ventral decubitus with large pads under the thorax and pelvis to reduce the pressure on the abdomen. The procedure consisted of decompression, reduction and fixation from $\mathrm{T} 1$ to $\mathrm{T} 7$ by means of a posterior route (Figure 2). The screws were placed based on anatomical reference points, and an image intensifier was used to check the reduction and the positioning of the implants, only at the end of the surgical procedure. At the time of discharge from hospital, 10 days after admission, she continued to present absence of sensitivity and motricity below T6, with a neurological injury classified on the Frankel scale ${ }^{(13)}$ as type A. According to the ASIA scale ${ }^{(14)}$, she presented 50 points for the motor index and 52 for sensory stimulation, with absence of partially innervated segments distal to the lesion (same score as on entry). She was then referred to physiatry and physiotherapy to aid in the recovery and adaptation to the special needs of a patient with a spinal cord injury.

Prenatal follow-up was maintained on an outpatient basis and, at the $39^{\text {th }}$ week of pregnancy, she went into delivery labor at her home, which was recognized through palpation of the uterine contractions, given that she could not feel the characteristic pain. She sought the hospital and, four hours after the start of delivery labor, a female child was born by means of normal delivery, without intercurrences. During the active phase of the dilation period, the patient received analgesia through an epidural catheter and did not present any signs of autonomic hyperreflexia. On the Apgar scale ${ }^{(15)}$, for initial assessment of new- borns, the child received an initial score of 5 and, after five minutes, a score of 10 . Today, at the age of two years, the child presents normal neuropsychomotor development for the age. The patient evolved with bone consolidation in the segment operated, as shown by tomography performed one year after the surgery (Figure 3). The study presented here was evaluated and approved by our institution's Research Ethics Committee (protocol number 12/10).

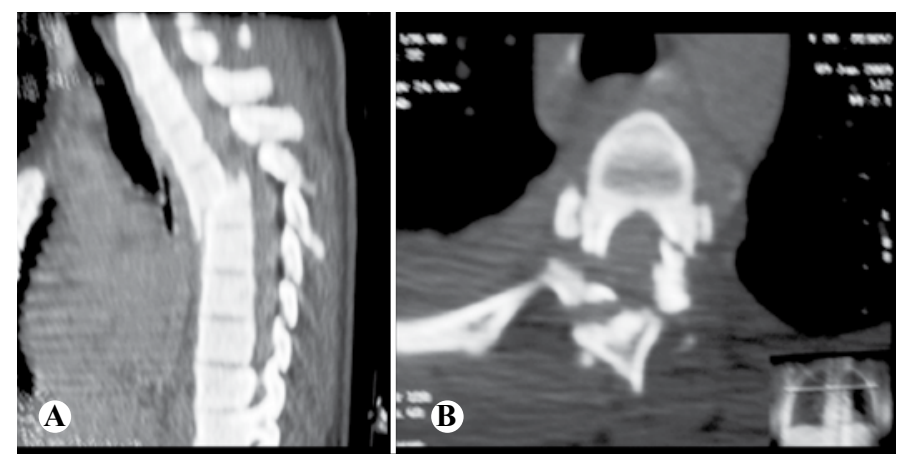

Figure 1 - (A) Computed tomography (sagittal slice) showing fracturing and dislocation at T4-T5 with compromised spinal canal. (B) Computed tomography (axial slice) showing complex injury of the posterior elements of T4.
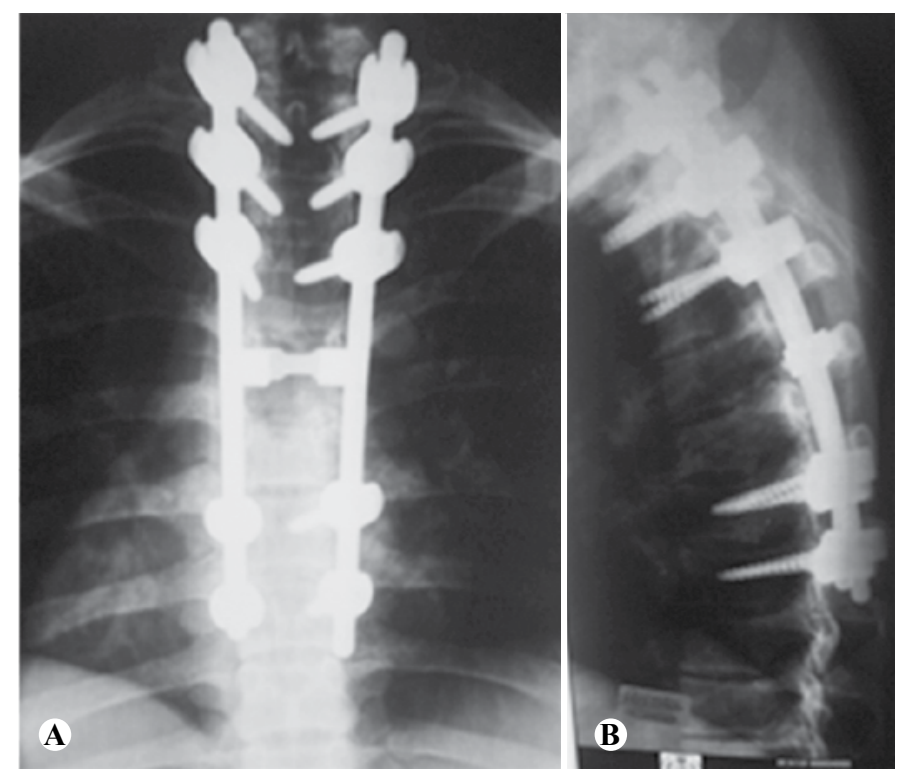

Figure 2 - (A) Anteroposterior radiograph in the immediate postoperative period. (B) Lateral radiograph in the immediate postoperative period, showing the restoration of the sagittal alignment.

\section{DISCUSSION}

The spinal fractures most commonly encountered during pregnancy are at the thoracolumbar transition. They are generally associated with systemic osteoporosis of pregnancy, do not cause spinal cord injury and are treated conservatively ${ }^{(16-18)}$. Only two case reports on spinal fractures with spinal cord injuries that were treated surgically during pregnancy 


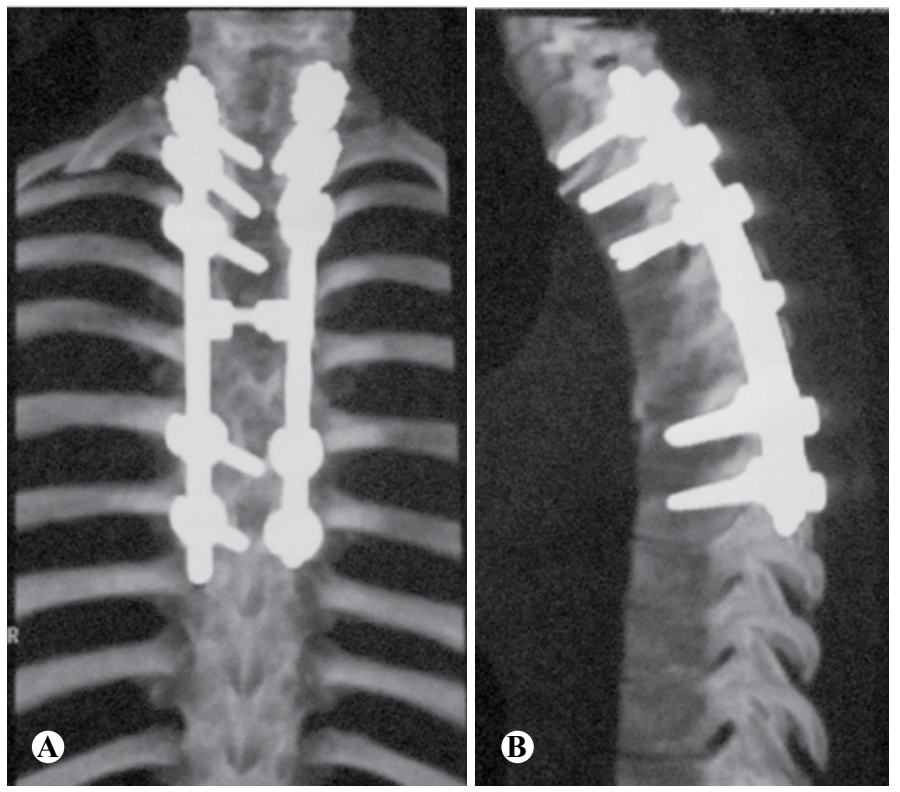

Figure 3 - Coronal $(A)$ and sagittal $(B)$ slices of computed tomography performed one year after the surgery, showing posterior fusion and adequate alignment of the spine.

are available in the literature. In both of those cases, the fracture occurred in the thoracic segment and the pregnancies were concluded with the birth of healthy children $^{(1,3)}$. In the case described by Paonessa and Fernand $^{(3)}$, a patient in her $22^{\text {nd }}$ week of pregnancy underwent reduction of fracturing and dislocation at T7-T8 and arthrodesis, by means of a posterior route, using Harri-Luque instruments. The patient evolved with spontaneous premature breakage of the membranes (in the $34^{\text {th }}$ week), and a cesarean delivery was then performed. In the case described by Lenarz et $\mathrm{al}^{(1)}$, a women in her $17^{\text {th }}$ week of pregnancy who had suffered an explosive fracture at T12, was treated with decompression, reduction and arthrodesis by means of an anterior route, and evolved without gestational intercurrences, with cesarean delivery performed at term.

Fractures with dislocation of the thoracic spine are associated with high-energy trauma and cause neurological lesions in the great majority of these patients. They need to be treated surgically, with the objective of achieving neural decompression, reduction and mechanical stabilization of the spine ${ }^{(19)}$. Most authors have advocated that the surgery should be performed as early as possible, provided that the patient's clinical state allows this approach, since this increases the chances of neurological recovery ${ }^{(20,21)}$. The presence of ongoing pregnancy is not a contraindication for surgical treatment of injuries of this type in the spine $e^{(1,3,22-24)}$. Our patient suffered fracturing and dislocation at T4-T5, which was classified as type $\mathrm{C} 3$ in accordance with Magerl et $\mathrm{al}^{(25)}$, and underwent surgical treatment 11 hours after the trauma. We chose to use a posterior route for reduction, decompression and fixation with pedicle screws, which provided adequate stability for treating these injuries ${ }^{(24,26)}$, with low morbidity.

Exposure of pregnant women to ionizing radiation may cause a variety of problems in the fetus. Surgeons have to be aware of the safe amount of radiation than can be used. This amount depends on the gestational age, as can be seen in Table 1. The teratogenic effects of radiation are caused mainly by exposure during the first trimester of pregnancy. After the $20^{\text {th }}$ week, the main concern becomes the oncogenic potential ${ }^{(27)}$.

Use of methylprednisolone at high doses for treating spinal cord trauma was described by Bracken et $\mathrm{al}^{(28-30)}$ and supported by several authors ${ }^{(31,32)}$. However, many researchers have questioned its benefit, given that risks such as increased incidence of infection, respiratory complications and problems in the gastrointestinal tract have been reported ${ }^{(33-35)}$. No studies on use of corticoid therapy have included the participation of pregnant patients, and therefore there is no information that might vouch for its efficacy and safety in this population ${ }^{(28-35)}$. For this reason, we did not use corticoid therapy on our patient.

Pregnant women with high spinal cord injuries maintain the capacity to go into delivery labor and conclude the pregnancy through normal delivery. This occurs because the start of delivery labor in women does not depend on the uterine autonomic innervation but on the action of hormones, especially oxytocin, which reaches the uterus by means of a hematogenic route $^{(22)}$. Regarding the delivery route, it is worth emphasizing that there is no contraindication against vaginal delivery, and that assisted normal delivery is the most recommended route ${ }^{(22,23,36)}$. Pregnant women

Table 1 - Maximum safe dose of ionizing radiation according to the gestational age.

\begin{tabular}{c|c}
\hline Gestational age (weeks) & Radiation dose (rads) \\
\hline$\leq 2$ & 5 \\
\hline 3 to 8 & 20 \\
\hline 8 to 15 & 30 \\
\hline 20 to delivery & Risk equivalent to that of adults \\
\hline Based on data from the Health Physics Society (27).
\end{tabular}


with spinal cord injuries above T10 present a high rate of unassisted delivery, since the afferent sensory fibers from the uterine nerves generally reach the spinal cord at the levels T11 to $\mathrm{L}^{(22)}$. Those with injuries above this level do not feel the normal pain of delivery labor and for this reason they may be late in seeking the hospital. To avoid this complication, our patient was trained to recognize her uterine contractions by means of palpation, along with other changes such as increased respiratory frequency and spasticity, which suggest that delivery labor is beginning.

It is also worth highlighting that the incidence of gestational complications is greater among patients with spinal cord injuries, particularly if the injury occurs during pregnancy. In these patients, increased risk of spontaneous abortion, premature delivery, fetal malformation and premature detachment of the placenta are observed ${ }^{(23)}$. Moreover, situations of repeated urinary infection, bed sores and deep vein thrombosis in the lower limbs (which may cause pulmonary thromboembolism) are seen with greater frequency ${ }^{(4,22,23,36)}$. These ailments need to be rapidly recognized and treatment, since they may impair the evolution of the pregnancy.

The most feared complication that can occur during the pregnancy of a patient with a spinal cord injury is autonomic hyperreflexia. This condition can be seen in up to $85 \%$ of the patients with spinal cord injuries above the exit level of the visceral autonomic nerves $(\mathrm{T} 5-\mathrm{T} 6)^{(4,22,23,36)}$, whereas it is rarely encountered when the injury occurs below T10. Autonomic hyperreflexia can occur at any time from the spinal cord shock to the puerperium, and it occurs most frequently during delivery labor. It can be triggered by pain, uterine contractions, bladder distension, intestinal distension, insertion of a urinary catheter or vaginal probing. The main sign of autonomic hyperreflexia is arterial hypertension, which is generally severe and may exceed levels such as 300 x $200 \mathrm{mmHg}$. Other signs and symptoms include tachycardia, fever, intense headache, nausea, facial rubor, dyspnea and convulsions. Conditions of autonomic hyperreflexia need to be differentiated from preeclampsia with the aid of laboratory tests, since the treatment is specific for each situation. In cases of hyperreflexia, therapy consisting of epidural anesthesia, spinal anesthesia or even inhaled general anesthesia is indicated, to attempt to control the abnormalities. In addition, intravenous antihypertensive agents are frequently used and cesarean delivery may be necessary. Use of analgesia during delivery labor reduces the risk of autonomic hyperreflexia ${ }^{(4,22,23,36)}$. Our patient received continual epidural analgesia around the time of delivery and did not present any symptoms of autonomic hyperreflexia.

Our experience has shown that several details need to be taken into consideration in treating pregnant women with acute spinal cord injuries: recognition and orthopedic treatment of the spinal and nerve injuries, care in using ionizing radiation, prevention and management of autonomic hyperreflexia and infections, training to recognize delivery labor, analgesia and deciding the delivery route. Only a multidisciplinary team composed by physicians from different specialties (spinal surgeons, obstetricians and physiatrists), nurses and physiotherapists is capable of assisting these patients, thereby increasing the chance that the pregnancy can progress safely for the mother and fetus.

\section{REFERÊNCIAS}

1. Lenarz CJ, Wittgen CM, Place HM. Management of a pregnant patient with a burst fracture causing neurologic injury. A case report. J Bone Joint Surg Am. 2009; 91(7):1747-9.

2. Tanchev $P$, Dikov D, Novkov $H$. Thoracolumbar distraction fractures in advanced pregnancy: a contribution of two case reports. Eur Spine J. 2000; 9(2):167-70.

3. Paonessa K, Fernand R. Spinal cord injury and pregnancy. Spine (Phila PA 1976). 1991;16(5):596-8.

4. Popov I, Ngambu F, Mantel G, Rout C, Moodley J. Acute spinal cord injury in pregnancy: an illustrative case and literature review. J Obstet Gynaecol. 2003;23(6):596-8.

5. Schnake KJ, Scholz M, Marx A, Hoffmann R, Kandziora F. Anterior, thoracoscopic-assisted reduction and stabilization of a thoracic burst fracture (T8) in a pregnant woman. Eur Spine J. 2011;20(8):1217-21.

6. Martínez-Padilla LA, Santana-Reyna MA, Díaz-Ruiz OS, Silva-Escalante D, Dufoo-Olvera M, García-López OF, et al. [Fracture dislocation of the thoraco-

lumbar spine in pregnant patient: diagnostic by image and treatment]. Acta Ortop Mex. 2010;24(2):100-7.

7. Masini M. Tratamento das fraturas e luxações da coluna toracolombar por descompressão póstero-lateral e fixação posterior com retângulo e fios segmentares sublaminares associados a enxerto ósseo [tese]. São Paulo: Universidade Federal de São Paulo, Escola Paulista de Medicina; 2000.

8. Campos MF, Ribeiro AT, Listik S, Pereira CAB, Andrade Sobrinho J, Rapoport A. Epidemiologia do traumatismo da coluna vertebral. Rev Col Bras Cir. 2008;35(8):88-93.

9. Oliveira PAS, Pires JV, Borges Filho JMM. Traumatismos da coluna torácica e lombar: avaliação epidemiológica. Rev Bras Ortop. 1996;31:771-6.

10. Fraga GP, Mantovani M, Mesquita AC, Soares AB, Passini Júnior R. Trauma abdominal em grávidas. Rev Bras Ginecol Obstet. 2005;27(9):541-7.

11. Corsi PR, Rasslam S, Oliveira LB, Kronfly FS, Marinho VP. Trauma na gestante: análise da mortalidade materna e fetal. Rev Col Bras Cir. 1999;26(2):79-83. 
12. American College of Surgeons. Advanced trauma life support 7th ed. Chicago: American College of Surgeons; 2004.

13. Frankel HL, Hancock DO, Hyslop G, Melzak J, Michaelis LS, Ungar GH,et al The value of postural reduction in the initial management of closed injuries of the spine with paraplegia and tetraplegia. I. Paraplegia. 1969;7(3):179-92.

14. American Spinal Injury Association: Standards for neurological classification of spinal injury patientes. Chicago, IL: Asia; 1989.

15. Apgar $\mathrm{V}$. A proposal for a new method of evaluation of the newborn infant. Curr Res Anesth Analg. 1953;32(4):260-7.

16. Sarikaya S, Ozdolap S, Açikgöz G, Erdem CZ. Pregnancy-associated osteoporosis with vertebral fractures and scoliosis. Joint Bone Spine. 2004;71(1):84-5

17. Bayram S, Ozturk C, Sivrioglu K, Aydinli U, Kucukoglu S. Kyphoplasty for pregnancy-associated osteoporotic vertebral fractures. Joint Bone Spine. 2006;73(5):564-6.

18. Smith R, Phillips AJ. Osteoporosis during pregnancy and its management. Scand J Rheumatol Suppl. 1998;107:66-7.

19. Vieira JSL, Herrero CFPS, Porto MA, Defino HLA. Tratamento cirúrgico das fraturas instáveis da coluna torácica. Coluna/Colunma. 2008;7(4):334-9.

20. Papadopoulos SM, Selden NR, Quint DJ, Patel N, Gillespie B, Grube S. Immediate spinal cord decompression for cervical spinal cord injury: feasibility and outcome. J Trauma. 2002;52(2):323-32.

21. Fehlings $M G$, Sekhon $L H$, Tator $C$. The role and timing of decompression in acute spinal cord injury: what do we know? What should we do? Spine (Phila Pa 1976). 2001; 26(Suppl 24):S101-10.

22. Pereira L. Obstetric management of the patient with spinal cord injury. Obstet Gynecol Surv. 2003;58(10):678-87.

23. Kuczkowski KM. Labor analgesia for the parturient with spinal cord injury: what does an obstetrician need to know? Arch Gynecol Obstet 2006;274(2):108-12

24. Han IH. Pregnancy and spinal problems. Curr Opin Obstet Gynecol. 2010;22(6):477-81.

25. Magerl F, Aebi M, Gertzbein SD, Harms J, Nazarian S. A comprehensive classification of thoracic and lumbar injuries. Eur Spine J. 1994;3(4):184-201.
26. Lim TH, An HS, Hong JH, Ahn JY, You JW, Eck J, et al. Biomechanical evaluation of anterior and posterior fixations in an unstable calf spine model. Spine (Phila Pa 1976). 1997;22(3):261-6.

27. Brent R. Pregnancy and radiation exposure. Health Physics Society; 2008 Jul 2. Disponível em: http://hps.org/hpspublications/articles/pregnancyandradiationexposureinfosheet.html.

28. Bracken MB, Shepard MJ, Collins WF, Holford TR, Young W, Baskin DS, et al. A randomized, controlled trial of methylprednisolone or naloxone in the treatment of acute spinal-cord injury. Results of the Second National Acute Spinal Cord Injury Study. N Engl J Med. 1990;322(20):1405-11.

29. Bracken MB, Shepard MJ, Holford TR, Leo-Summers L, Aldrich EF, Fazl M,et al. Administration of methylprednisolone for 24 or 48 hours or tirilazad mesylate for 48 hours in the treatment of acute spinal cord injury. Results of the Third National Acute Spinal Cord Injury Randomized Controlled Trial. National Acute Spinal Cord Injury Study. JAMA. 1997;277(20):1597-604.

30. Bracken MB. Pharmacological interventions for acute spinal cord injury. Cochrane Database Syst Rev. 2000;(2):CD001046.

31. Barros Filho TEP. Tratamento medicamentoso no traumatismo raquimedular. Rev Bras Ortop. 2000;35(5):143-6

32. Tsutsumi S, Ueta T, Shiba K, Yamamoto S, Takagishi K. Effects of the Second National Acute Spinal Cord Injury Study of high-dose methylprednisolone therapy on acute cervical spinal cord injury-results in spinal injuries center. Spine (Phila Pa 1976). 2006;31(26):2992-6.

33. Hurlbert RJ. The role of steroids in acute spinal cord injury: an evidence-based analysis. Spine (Phila Pa 1976). 2001;26(Suppl 24):S39-46.

34. Sayer FT, Kronvall E, Nilsson OG. Methylprednisolone treatment in acute spinal cord injury: the myth challenged through a structured analysis of published literature. Spine J. 2006; 6(3):335-43.

35. Hugenholtz $\mathrm{H}$. Methylprednisolone for acute spinal cord injury: not a standard of care. CMAJ. 2003; 168(9):1145-6.

36. American College of Obstetrics and Gynecology. ACOG committee opinion. Obstetric management of patients with spinal cord injuries. Number 275, September 2002. Committee on Obstetric Practice. American College of Obstetrics and Gynecology. Int J Gynaecol Obstet. 2002;79(2):189-91. 